\title{
Pola Relasi Antara Komunitas Ashram dengan Wisatawan di Ashram Ratu Bagus sebagai Daya Tarik Wisata
}

Chris Janitra Williama, 1, Luh Putu Kerti Pujani 2a, 2

11chrisjanitra2017@gmail.com 1,2kerti_pujani@unud.ac.id2

a Program Studi Sarjana Destinasi Pariwisata, Fakultas Pariwisata, Universitas Udayana, Jl. Dr. R. Goris, Denpasar, Bali 80232 Indonesia

\section{Abstract}

Ashram Ratu Bagus is spiritual tourist attraction located in Muncan Village, Karangasem Regency. Ashram Ratu Bagus has a spiritual teacher called Ratu Bagus and unqiue spiritual activity called Bio-Energy Meditation or Shaking Yoga difference them with other spiritual attraction. This study aims to research relationship pattern that being formed between ashram community and tourist in Ashram Ratu Bagus as tourist attraction. The research method used in this study is a qualitative and quantitative data types. Source of data that being used is primary and secondary data. Data collection techniques used are participation observation technique, unstructured interviews also document study. Informant determination using purposive sampling. Data analysis is descriptive qualitative analysis. The result of this research points out that the relationship pattern between ashram community and tourist in Ashram Ratu Bagus as tourist attraction occur because tourist want to relieve themselves, want to have serious recreation, find their trueself and interested to utilize their leisure time with spiritual education in ashram and interact with Ratu Bagus and ashram community. The relationship being formed between Ratu Bagus and tourist is teacher and student wheres Ratu Bagus as their spiritual teacher, and the relationship being formed with ashram community is familial bonds where they're living together in same place and learning the depth of spirituality together. The relation that being formed in Ashram Ratu Bagus is a real example of potency can be created between community and tourist.

\section{Keyword: Relationship Pattern, Ashram Ratu Bagus, Tourist Attraction}

\section{PENDAHULUAN}

Pariwisata merupakan kumpulan fenomena dan hubungannya yang muncul dari interaksi antara wisatawan, pemasok, pemerintah daerah tujuan wisata, komunitas daerah tujuan wisata, pemerintah asal wisatawan, universitas, komunitas mahasiswa dan lembaga swadaya masyarakat, yang didalamnya terdapat proses menarik, mentransportasikan, melayani dan mengelola para turis serta pengunjung lainnya. Dalam fenomena pariwisata sangat erat kaitannya dengan hubungan interaksi host-guest dari hasil proses pelayanan kepada tamu oleh tuan rumah. Keberadaan pariwisata tidak hanya terkait dengan ekonomi melainkan ragam dimensi-dimensi seperti sosial, budaya, psikologi, politik, hukum, lingkungan dan yang lainnya (Fridgen, 1991; Weaver dan Opperman dalam Pitana, 2005).

Pada abad ke-20 pariwisata telah menjadi pilihan negara dunia ketiga dalam mengembangkan perekonomiannya (Reid,2003). Salah satunya adalah Indonesia yang memanfaatkan industri pariwisata sebagai sumber perekonomianya yang pada tahun 2019 telah menghasilkan devisa sebesar 19,29 Miliar Dolar AS dengan kontribusi sektor terhadap Pendapatan Domestik Bruto (PDB) sebesar 4,80\% (Kemenparekraf, 2019). Fenomena pariwisata sebagai fenomena kompleks memang sangat menguntungkan secara ekonomi, namun keberlangsungan interaksi dan hubungan yang baik merupakan salah satu cara yang diperlukan agar Indonesia dapat mempertahankan kunjungan dari relasi antara host-guest yang berkelanjutan. Dalam hal ini Indonesia telah memiliki Provinsi Bali yang telah berkecimpung dalam sektor pariwisata sejak tahun 1920-an (Budarma, 2012), yang menunjukkan Bali telah 1 abad mengembangkan sektor pariwisata.

Provinsi Bali dengan keragaman bentang alam dan budaya yang indah menyediakan berbagai paket wisata lengkap untuk wisatawan. Seperti Kuta yang diidentikan dengan surfing, Tulamben yang diidentikandengan diving, Gunung Batur yang diidentikan dengan trekking, Gunung Agung yang diidentikan dengan hiking.

Salah satu daya tarik wisata yang sudah lama ada di Bali, yaitu Ashram Ratu Bagus yang terkenal dengan aktivitas spiritual tourism atau wisata spiritual yang ditawarkan. Spiritual tourism atau wisata spiritual adalah jenis pariwisata yang termasuk pada aliran wisata minat khusus atau special interest tourism dan merupakan salah satu jenis wisata tertua yang berkembang di Bali semenjak pariwisata merasuki Bali.

Ashram Ratu Bagus telah menerima kunjungan wisatawan pertama sejak tahun 1993 yang menandakan 2,5 dekade Ashram Ratu Bagus telah beroperasi dalam praktik pariwisata spiritual, Ashram Ratu Bagus juga memiliki aktivitas meditasi yang dikenal dengan istilah Meditasi Bio-Energi atau Shaking Yoga yang merupakan yoga aktif sebagai unique point dari aktivitas wisata spiritual khusus yang dimiliki pashraman. Ashram Ratu Bagus telah berhasil membina hubungan host-guest yang baik sejak awal pendiriannya dan mendapatkan kunjungan wisatawan yang berkelanjutan. Ashram Ratu Bagus sebagai tempat pendidikan spiritual memiliki seorang guru spiritual, yaitu Ratu Bagus yang membina murid-muridnya baik lokal dan mancanegara, yaitu komunitas ashram dan 
wisatawan yang menempuh pendidikan spiritual di Ashram Ratu Bagus, sehingga tercipta relasi antara pihak-pihak tersebut di daya tarik wisata Ashram Ratu Bagus.

Dari pemaparan uraian latar belakang, menarik untuk dilakukan penelitian dengan mengangkat isu pola relasi yang terbentuk antara komunitas ashram dengan wisatawan di Ashram Ratu Bagus sebagai daya tarik wisata. Penelitian bertujuan memberikan penjelasan dan gambaran mengenai bagaimana relasi yang dapat terbentuk antara komunitas ashram dengan wisatawan di Ashram Ratu Bagus, serta manfaat dari penelitian yang mengungkap pola relasi yang dapat terbentuk antara komunitas ashram dengan wisatawan serta potensi capaian relasi yang dapat terbentuk dari praktik wisata spiritual.

Telaah penelitian sebelumnya sangat penting dilakukan untuk mengetahui posisi penelitian yang dilakukan dengan yang sudah ada ada sebelumnya sehingga tidak terjadi penelitian ganda. Telaah penelitian pertama yang berkaitan dengan fokus penelitian yaitu penelitian yang berjudul "Host-Guest Relationship in Tourism: Evidence from Two Portuguese Villages" (Kastenholz et al., 2013). Telaah penelitian sebelumnya kedua berkaitan dengan fokus penelitian berjudul "Tourist Community Interaction in Ethnic Tourism: Tuva Villages, Kanas Scenic Area, China" (Su et al,. 2014). Telaah penelitian sebelumnya ketiga berkaitan dengan lokasi penelitian berjudul "Studi Saluran Distribusi Produk Pariwisata Spiritual di Ashram Ratu Bagus" (Ika, 2018). Telaah penelitian sebelumnya keempat berkaitan dengan lokasi penelitian berjudul "Wisata Spiritual: Studi Kasus Partisipasi Orang Asing dalam Upacara Pitrayajña di Desa Pakraman Muncan, Selat, Karangasem" (Narottama, 2012). Telaah penelitian sebelumnya kelima berkaitan dengan lokasi penelitian berjudul "Daya Tarik Utama Ashram Ratu Bagus sebagai Tujuan Wisata Spiritual dan Manfaatnya terhadap Wisatawan Mancanegara di Desa Muncan, Kecamatan Selat, Kabupaten Karangasem" (Ariawan, 2009). Perbedaan telaah penelitian sebelumnya dengan penelitian saat ini terlihat dari fokus terjadinya pola relasi antara hostguest pada fenomena pariwisata yang berbeda dimana penelitian pertama di wisata pedesaan, dan penelitian kedua pada wisata etnik sedangkan penelitian saat ini pada aktivitas wisata spiritual dan tempat yang berbeda, serta perbedaan terkait lokasi penelitian telaah sebelumnya terletak pada fokus dimana penelitian di Ashram Ratu Bagus masih belum adanya telaah mengenai relasi komunitas ashram dengan wisatawan.

Dalam menganalisis permasalahan artikel penelitian digunakan, serangkaian konsep analisis. Konsep-konsep yang digunakan sebagai analisis permasalahan, meliputi konsep pariwisata spiritual (Yoeti dalam Ika, 2018), konsep wisatawan spiritual
(Haq \& Jackson, 2006), konsep faktor pendorong dan penarik motivasi wisatawan (Pitana dan Gayatri, 2005), konsep interaksi Sosial (Soekanto, 2007), konsep relasi sosial (Spradley dan McCurdy 1975), konsep komunitas (Kertajaya, 2008), konsep sosiologi keluarga (Soelaeman dalam Shochib, 2000).

\section{METODE PENELITIAN}

Penelitian ini dilaksanakan di Daya Tarik Wisata Ashram Ratu Bagus yang terletak di Desa Muncan, Kecamatan Selat, Kabupaten Karangasem yang berjarak $\pm 50 \mathrm{~km}$ dari ibukota Denpasar. Ashram Ratu Bagus terletak dekat dengan Gunung Agung dan Pura Besakih. Penelitian memilih lokasi Ashram Ratu Bagus dikarenakan keunikan relasi yang terbina oleh komunitas ashram dengan wisatawan dan ashram yang selalu berkelanjutan mendapatkan kunjungan wisatawan. Penelitian dilakukan selama tiga bulan pada tahun 2020 . Ruang lingkup penelitian, meliputi dari faktorfaktor pendorong dan penarik wisatawan dalam mengunjungi Ashram Ratu Bagus, pola relasi antara Ratu Bagus dengan wisatawan di Ashram Ratu Bagus, dan pola relasi antara komunitas ashram dengan wisatawan di Ashram Ratu Bagus.

Jenis data yang digunakan dalam penelitian ini adalah kualitatif dan kuantitatif (Kusmayadi \& Sugiarto, 2000). Sumber data dalam penelitian diperoleh meliputi data primer yang diperoleh langsung dari lapangan (Sugiyono, 2014), meliputi; informasi mengenai, profil dari daya tarik wisata Ashram Ratu Bagus, pelayanan Ashram Ratu Bagus, kunjungan wisatawan yang mengunjungi Ashram Ratu Bagus, faktor-faktor pendorong dan penarik wisatawan dalam mengunjungi Ashram Ratu Bagus, pola relasi antara Ratu Bagus dengan wisatawan, pola relasi antara komunitas Ashram Ratu Bagus dengan wisatawan dan data sekunder yang diperoleh dari sumber kedua (Moleong, 2005), meliputi; portofolio Ratu Bagus. kunjungan wisatawan ke Ashram Ratu Bagus, jumlah staf di Ashram Ratu Bagus dan lokasi Ashram Ratu Bagus pada denah Desa Muncan.

Teknik pengumpulan data yang digunakan dalam penelitian ini adalah observasi partisipasi (Sugiyono, 2017), wawancara tidak terstruktur (Sugiyono, 2017) dan studi dokumen (Bowen, 2009). Observasi partisipasi digunakan untuk memperoleh data pola relasi komunitas ashram dengan wisatawan di Ashram Ratu Bagus sebagai daya tarik wisata, wawancara digunakan untuk menggali faktor pendorong dan penarik wisatawan dalam mengunjungi Ashram Ratu Bagus, pola relasi komunitas ashram dengan wisatawan di Ashram Ratu Bagus sebagai daya tarik wisata, dan studi dokumen digunakan untuk memperoleh protofolio Ratu Bagus, data kunjungan wisatawan ke Ashram Ratu Bagus, jumlah staf di Ashram Ratu Bagus, dan 
lokasi Ashram Ratu Bagus pada denah Desa Muncan.

Teknik analisis data yang digunakan pada penelitian ini adalah teknik analisis data kualitatif menurut Cresswell (Sugiyono, 2017). Adapun teknik analisis data, berproses dengan; 1) mengorganisasikan dan menyiapkan data yang akan dianalisis, 2) baca dan lihat seluruh data, 3) membuat koding seluruh data, 4) menggunakan koding sebagai bahan untuk membuat deskripsi, 5) menghubungkan antara tema, 6) memberi interprestasi dan makna dari tema. Dalam hal ini peneliti mengorganisasikan dan menyiapkan data mentah yang telah dikumpulkan untuk dianalisis, membaca keseluruhan data, membuat koding dari seluruh data yang telah dibaca, memanfaatkan koding untuk memberikan deskripsi, menghubungkan koding dengan tema penelitian, memberi interprestasi dan makna dari tema untuk menjawab isu pola relasi komunitas ashram dengan wisatawan di Ashram Ratu Bagus sebagai daya tarik wisata.

\section{HASIL DAN PEMBAHASAN}

\section{A. Gambaran Umum Ashram Ratu Bagus}

Ashram Ratu Bagus merupakan daya tarik wisata yang menawarkan aktivitas wisata spiritual, berdiri pada lahan seluas 20 hektar dan masih kokoh mempertahankan arsitektur Bali pada keseluruhan bangunannya. Terletak di wilayah administratif Kabupaten Karangasem, Kecamatan Selat, Desa Muncan dengan lokasi berdekatan dengan hamparan persawahan dan Pura Besakih serta Gunung Agung menjadikan Ashram Ratu Bagus sebagai salah satu tempat yang memiliki nuansa spiritual yang kuat. Gambar 1. Lokasi Ashram

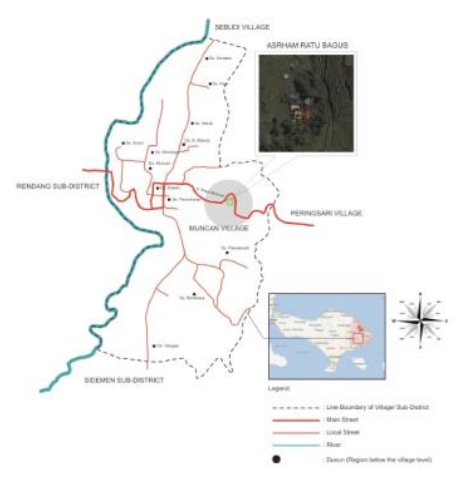

Ratu Bagus dalam Denah Desa Muncan Sumber: Wardhani dalam Narottama (2012)

Ashram Ratu Bagus pertama kali berdiri pada September 1998, serta pada tahun 1993 Ashram Ratu Bagus pertama kalinya melakukan penerimaan pada murid-murid dari Barat. Ashram Ratu Bagus terkenal dengan ajarannya mengenai Meditasi BioEnergi (Bio-Energy Meditation atau Shaking Yoga). Ratu Bagus sebagai guru spiritual lebih menekankan pada praktek yang dilakukan secara serius dan rutin. Dengan adanya vibrasi yang tinggi dari energi, kita dapat merasakan tubuh bergetar, bergerak secara spontan, menjadi tertawa atau pelepasan emosi, yang berlangsung secara sederhana namun penuh kekuatan. Ashram Ratu Bagus sebagai daya tarik wisata minat khusus menghadirkan jenis wisata spiritual yang menyongsong aktivitas Meditasi BioEnergi atau Shaking Yoga sebagai unique point dari pashraman yang membedakannya dengan pashraman lainnya. Melalui Meditasi Bio-Energi seseorang dapat terkoneksi dengan Ratu Bagus, jiwa sesama sisya serta mampu merasakan, Tuhan dalam diri dan menemukan pembentukan dari jati diri.

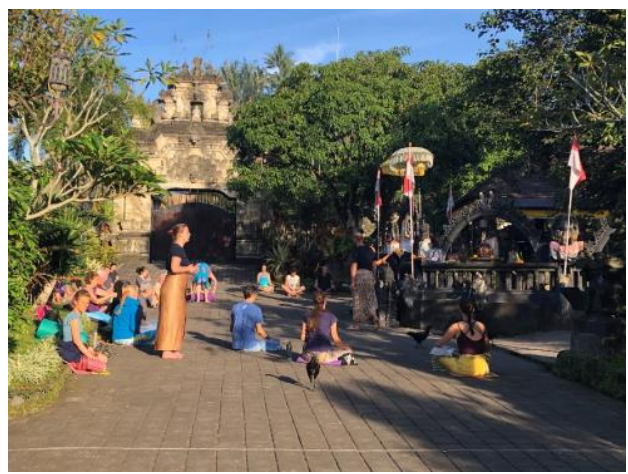

Gambar 2. Sesi Shaking Pagi di Taman

Sumber: Dokumentasi Penelitian Lapangan, 2020

Ashram Ratu Bagus dikelola oleh personelpersonel yang merupakan murid-murid Ratu Bagus, keseluruhan dari staf ashram merupakan murid Ratu Bagus yang memiliki jiwa pelayanan yang tinggi. Jumlah staf yang melakukan ngayah di Ashram Ratu Bagus terdiri dari Laki-laki dan perempuan dengan jumlah total sebanyak 24 orang yang bertanggung jawab pada tugasnya masingmasing. Ashram Ratu Bagus layaknya institusiinstitusi pada umumnya yang memiliki struktur dalam pengoperasiannya sehari-hari, struktur Ashram Ratu Bagus terbentuk dari 27 orang yang dari pembina, asisten pembina I dan II, wakil ketua, bendahara I dan II, sekretaris II dan II sampai dengan seksi-seksi terbagi dalam masing-masing bidang, kebanyakan orang-orang yang menjadi bagian dari struktur Ashram Ratu Bagus dalam pengoperasian ashram merupakan murid-murid atau sisya dari Ratu Bagus yang sudah sejak lama bersama dengan Ratu Bagus menjalankan manajemen ashram. Beliau sebagai guru spiritual dan master energi telah mengajarkan kepada sisya atau siswa-siswanya yang sekarang mengabdi pada institusi ashram mengenai kebebasan dari penderitaan, kecemasan dan rasa takut. Ratu Bagus telah membekali murid-muridnya mengenai pengetahuan spiritual, sehingga ketika wisatawan yang memerlukan bantuan murid-muridnya dapat memberikan saran terkait pemahaman praktik meditasi di Ashram Ratu Bagus. Murid-murid beliau 
Vol. 8 No 2, 2020

dalam pengoperasian ashram sampai sekarang ini berjumlahkan 50 orang yang memiliki peran memberikan pelayanan kepada tamu atau pengunjung baik wisatawan lokal maupun mancanegara yang mencari pengembangan spiritual dan penyembuhan pada beliau.

Ashram Ratu Bagus didirikan dan dimiliki oleh Ida Pandita Mpu Nabe Parama Daksa Ratu Bagus atau lebih dikenal dengan panggilan Ratu Bagus yang lahir di Sangging, Gianyar 24 November 1949. Ratu Bagus memilih untuk tinggal di Desa Muncan, Karangasem untuk melanjutkan hidup sebagai petani serta keinginan beliau untuk lebih dekat terhubung dengan semesta dan pencipta. Pada saat beliau bermeditasi di Gunung Agungbeliau menerima visi dari Tuhan dan diberi nama "Ratu Bagus Jaya Kesuma Kawi" dan mendapat ilham dari Tuhan bahwa beliau memiliki misi penting untuk meringankan penderitaan umat manusia dan bahwa beliau akan diberi kekuatan dan pengetahuan dalam memenuhi tugasnya. Pada bulan September 1988 Ashram Ratu Bagus didirikan sampai dengan sekarang beliau dengan sepak terjangnya dikenal baik di komunitas lokal dan luar negeri. Pada tahun 2007 beliau diangkat menjadi sulinggih dan mendapatkan gelar "Ida Pandita Mpu Nabe Prama Daksa Natha Ratu Bagus". Ratu Bagus hingga saat ini masih aktif dalam menjalankan tugasnya untuk membantu meringankan penderitaan orang lain

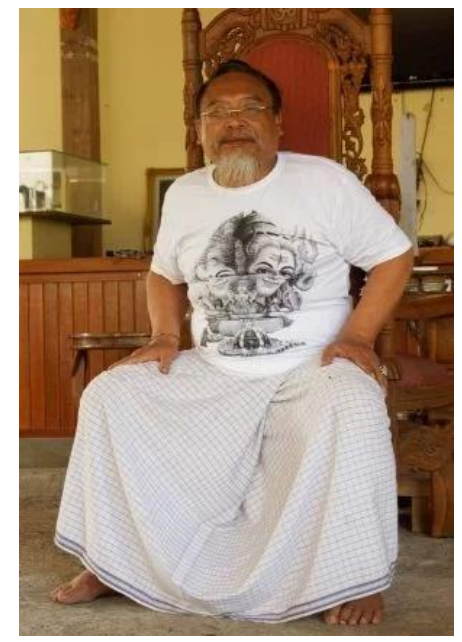

tanpa memandang latar belakang.

Gambar 3. Ida Pandita Mpu Nabe Prama Daksa Ratu Bagus

Sumber: www.ratubagus.com

Ashram Ratu Bagus dalam operasionalnya menyediakan pelayanan pemesanan(booking) secara digital melalui $e$-mail atau menghubungi nomor tertera di website (ratubagus.com). Ashram Ratu Bagus menyediakan pelayanan jasa yang cukup lengkap dimulai jasa antar-jemput ke bandara, pelayanan visa untuk wisatawan yang ingin memperpanjan visa, penyediaan akomodasi dengan sembilan jenis tipe kamar yang dibebas biayakan pada anak-anak dibawah 6 tahun dan setengah harga untuk 7-12 tahun jenis kamar dimulai disediakan dari tipe homestay, villa sampai dengan tipe bungalow. Selain itu, disediakan pula fasilitas restoran dengan penyediaan makanan tiga kali, pijat tisue, kolam renang, toko souvenir, perjalanan ke pantai, sumber mata air panas dan pasar kesenian, akses internet, dan fasilitas laundry.

\section{Gambar 4. Kamar Tipe Bungalow}

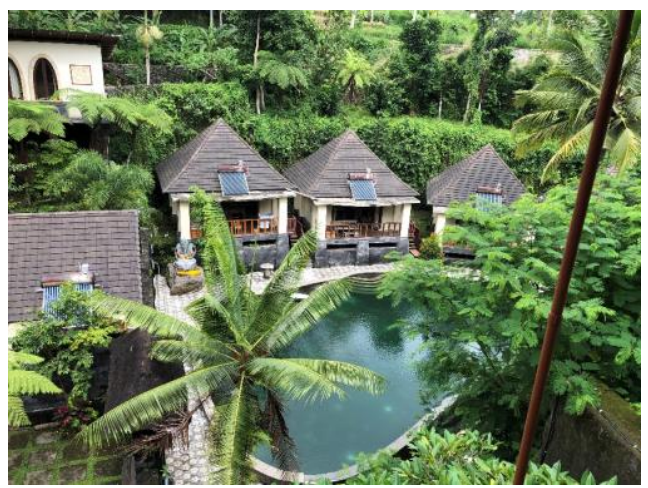

Sumber: Dokumentasi Penelitian Lapangan, 2020

Ashram Ratu Bagus sebagai daya tarik wisata mampu menampung 50-60 orang dalam penginapan yang tersedia di ashram, sehingga kunjungan terbanyak dapat mencapai 720 orang dan terendah 600 orang dalam setahun kunjungan wisatawan mancanegara ke Ashram Ratu Bagus dapat dilihat pada Tabel 1. sebagai berikut;

\section{Tabel 1. Data Kunjungan Wisatawan Mancanegara ke Ashram Ratu Bagus} Tahun 2015-2019

\begin{tabular}{cccc}
\hline Tahun & Kunjungan & Rata-rata & Pertumbuhan \\
wisatawan & okupansi & $(\%)$ \\
mancanegara & ashram & \\
dalam & dalam & \\
setahun & sebulan & \\
& & (orang) &
\end{tabular}

\begin{tabular}{llll}
\hline 2015 & 803 & 67 & - \\
\hline 2016 & 727 & 61 & $-9,46 \%$ \\
\hline 2017 & 635 & 53 & $-12,6 \%$ \\
\hline 2018 & 633 & 53 & $-0,31 \%$ \\
\hline 2019 & 655 & 55 & $3,47 \%$ \\
\hline
\end{tabular}

Sumber: Dokumen Penelitian Lapangan, 2020

Dari tabel 1 kunjungan wisatawan diketahui bahwa jumlah terbanyak kunjungan wisatawan terjadi di tahun 2015 setelah itu menurun dan naik kembali di tahun 2019. Pada tahun 2017-2018 dapat diketahui terjadi penurunan akibat erupsi Gunung Agung yang berdampak pada banyak negara yang mengeluarkan travel advisory dan travel warning sehingga dapat menjadi salah satu penyebab penurunan kunjungan. Namun, Ashram Ratu Bagus merupakan daya tarik wisata minat khusus yang 
menjalankan praktik wisata spiritual, sehingga jumlah kunjungan semata tidak dapat dijadikan tolak ukur kesuksesan wisata spiritual di Ashram Ratu Bagus. Keberhasilan pelaksanaan kepariwisataan di Ashram Ratu Bagus dapat dikatakan berhasil dengan jumlah repeater guest di ashram yang selalu mengisi akomodasi tiap tahunnya, dengan jumlah carrying capacity ashram menampung 600-720 orang. Banyak dari wisatawan spiritual yang mengunjungi ashram di dominasi dari Benua Eropa, Australia dan Amerika Serikat serta negara-negara lainnya. Walaupun pelaksanaan wisata spiritual di Ashram Ratu Bagus berbasis filosofi Hindu namun dalam praktiknya Ratu Bagus selalu menekankan kepada ke universal-an ajaranajarannya ke wisatawan.

\section{B. Faktor-Faktor Pendorong dan Penarik Wisatawan dalam Mengunjungi Ashram Ratu Bagus}

Wisatawan spiritual yang melakukan wisata spiritual di Ashram Ratu Bagus dalam kunjungan pertamanya akan menginap dalam kurun waktu satu minggu dan banyak dari lainnya memperpanjang kunjungan menjadi dua sampai dengan tiga minggu karena sudah mampu merasakan efek atau hasil dari pelatihan Meditasi Bio-Energi. Wisatawan yang berkunjung ke Ashram Ratu Bagus kebanyakan dalam rentan umur produktif 15-64 tahun yang rata-rata sudah bekerja dan mampu mencukupi kebutuhannya, serta kunjungan wisatawan ke ashram kebanyakan dalam bentuk kunjungan individu dan berpasangan tidak jarang pula ditemukan dalam bentuk sekelompok keluarga.

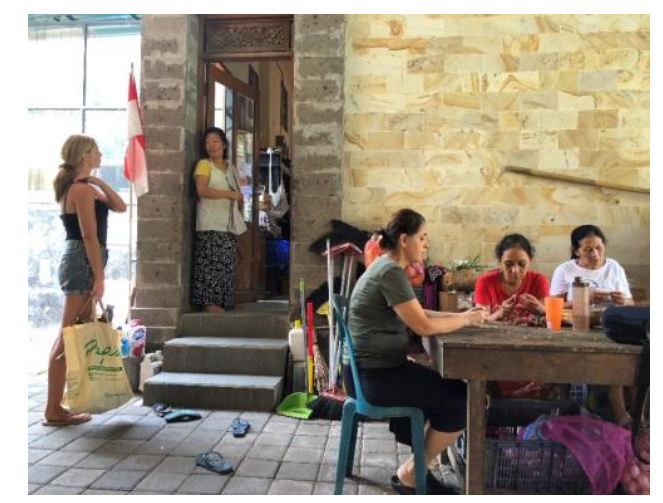

Gambar 5. Wisatawan yang Baru Datang ke Ashram Ratu Bagus

Sumber: Dokumentasi Penelitian Lapangan, 2020

Wisatawan yang berkunjung ke Ashram Ratu Bagus merupakan wisatawan minat khusus pada jenis wisata spiritual, yang secara umum dorongan mereka untuk melakukan perjalanan ke Ashram Ratu Bagus untuk melepas kejenuhan dari kehidupan sehari-hari, namun secara khusus wisatawan spiritual didorong oleh keinginan yang kuat untuk melakukan rekreasi serius yang muncul dari batin mereka secara mental dan emosional dalam pencarian self-fulfilment, yaitu keinginan menemukan jati diri mereka, pencarian makna dalam diri dan hidup yang hakiki. Alasan lainnya yang lebih khusus dari dorongan sosial-psikologis atau person specific motivation adalah pada saat mereka dalam kondisi sakit, mencari opsi pengobatan spiritual yang membuat mereka melakukan perjalanan spiritual ke Ashram Ratu Bagus.

Ashram Ratu Bagus sebagai daya tarik wisata merupakan tempat tujuan spiritual yang banyak didatangi oleh wisatawan dari Benua Eropa, Australia dan Amerika Serikat serta banyak negaranegara lainnya juga, lokasi Ashram Ratu Bagus sebagai episentrum spiritual yang berdekatan dengan Gunung Agung dan Pura Besakih membuat citra dan aura spiritual di Ashram Ratu Bagus sangat kental sehingga sangat cocok sebagai tempat untuk orang-orang yang mencari pengembangan spiritual. Ashram Ratu Bagus sebagai faktor penarik wisatawan memiliki destination specific attributes, yaitu bagaimana wisatawan tertarik karena peluang mereka untuk memperdalam spiritualitas mereka dengan peluang edukasi dan interaksi sosial dengan seorang guru dan komunitas Ratu Bagus, dimana di Ashram Ratu Bagus terdapat guru spiritual yang membimbing mereka dalam kehidupan dan selanjutnya banyak dari mereka juga datang kembali ke ashram selain kedua alasan utama mereka juga untuk menguatkan ikatan yang telah bangun dengan komunitas ashram sebagai kerabat mereka di Bali.

\section{Pola Relasi Antara Ratu Bagus dengan Wisatawan di Ashram Ratu Bagus}

Kata Ashram berasal dari bahasa Sansekerta yang berarti padepokan spiritual (suatu tempat untuk belajar kerohanian), (Goswani dalam Ariawan, 2009:70). Ashram Ratu Bagus sebagai pashraman atau padepokan spiritual memiliki guru yang bernama Ida Pandita Mpu Nabe Parama Daksa Natha Ratu Bagus atau biasa dikenal dengan panggilan Ratu Bagus. "Ashram Ratu Bagus dan Meditasi Bio-Energi beliau terbuka bagi semua orang, dan bagi semua umur. Yang diperlukan hanya dedikasi untuk penyembuhan dan komitmen untuk berkerja dan bermanfaat bagi orang lain. Tertawa, dukungan dan cinta memungkinkan para muridnya menikmati pengalaman transformasi. Biasanya direkomendasikan minimum tinggal selama lima hari, agar dapat terhubung dengan energi suci dan memulai perjalanan untuk penyembuhan.", (Narottama, 2012:114).

Layaknya sebuah pesantren dalam agama Islam yang dipimpin oleh seorang kiai, eksistensi ashram dalam agama Hindu maupun Buddha sebagai tempat pembelajaran spiritual didukung dengan keberadaaan guru spiritual. Ashram Ratu Bagus ditopang dengan kehadiran Ratu Bagus 
sebagai guru spiritual. Wisatawan yang berkunjung di Ashram Ratu Bagus akan menjadi murid Ratu Bagus dalam pembelajaran spiritualitas, Ratu Bagus sebagai guru spiritual memberikan ajaran-ajaran dalam hal filosofi-filosofi kehidupan serta cara menangani masalah proses dalam mempelajari Meditasi Bio-Energi dan manfaat melakukan Meditasi Bio-Energi atau Shaking Yoga. Selain itu, Ratu Bagus mengajarkan cara mencapai kedamaian dan kebebasan pada diri, cara memanfaatkan kinerja energi murni dalam diri, dan tata cara berkehidupan yang harmonis dengan Tuhan, alam dan sesama manusia melalui pembabaran Dharmawacana yang selalu diisi sebelum dan sesudah sesi shaking pagi, siang dan malam. Pola relasi guru dan murid tercipta di Ashram Ratu Bagus dengan kesediaan dari dalam diri wisatawan yang juga disebut sebagai sisya mancanegara untuk menerima ajaran-ajaran beliau.

\section{Gambar 6. Sesi Dharmawacana}

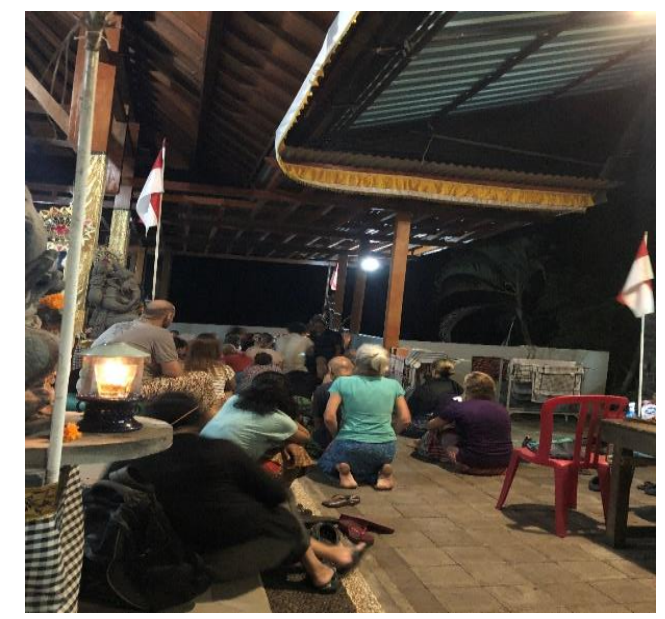

Sumber: Dokumentasi Penelitian Lapangan, 2020

Selama sisya mancanegara berkehidupan di Ashram Ratu Bagus mereka menjalani pendidikan spiritual, diajak untuk bersama-sama mencapai tingkat pemahaman spiritualitas yang lebih tinggi. Sisya mancanegara diajarkan bahwa hidup adalah karma yoga, mereka ikut belajar untuk hidup tanpa pamrih di dalam sebuah komunitas ashram dibawah arahan Ratu Bagus sebagai guru spiritual mereka. Ratu Bagus memberikan keleluasaan bagi seluruh komunitas ashram termasuk didalamnya sisya mancanegara yang terbina di ashram untuk melakukan pengembangan spiritual mereka. Pola Relasi guru dan murid antar Ratu Bagus dengan wisatawan telah dibina sejak tahun 1993 saat kedatangan wisatawan mancanegara pertama kali ke ashram sampai dengan sekarang bentuk hubungan ini merupakan bentuk nyata dari aktivitas pariwisata spiritual di Ashram Ratu Bagus yang otentik dengan aktivitas Meditasi Bio-Energi atau Shaking Yoga.

Wisatawan yang menjadi sisya dari Ratu Bagus dalam berkehidupan di Ashram dan bersama komunitas didalamnya menata kembali kehidupannya dengan mengikuti tatanan cara berkehidupan yang berlaku di Ashram Ratu Bagus sesuai anjuran dari Ratu Bagus. Berkehidupan sebagai sisya dari Ratu Bagus dan kepercayaan yang terbentuk dari hubungan guru spiritual dan murid membentuk karakter baru dalam diri mereka. Ratu Bagus sebagai guru spiritual membantu membimbing dan menyadarakan sumber masalah dari kesehatan fisik dan mental yang mereka alami, serta perbaikan karakter pada diri melalui pelaksanaan rutinitas Meditasi Bio-Energi atau Shaking Yoga. Pembelajaran spiritual yang diajarkan Ratu Bagus kepada wisatawan yang menjadi sisya membantu mereka untuk menyadari potensi diri tertinggi yang dapat dicapai oleh masing-masing individu.

Relasi guru spiritual dan murid yang terbentuk antara Ratu Bagus dengan wisatawan yang berkunjung ke Ashram Ratu Bagus dilandasi dengan kepercayaan wisatawan untuk berserah diri untuk menjadi siswa dari Ratu Bagus dan memperdalam pemahaman spiritualitas mereka, serta kepercayaan untuk mengikuti bimbingan Ratu Bagus sebagai guru spiritual.

\section{Pola Relasi Komunitas Ashram dengan Wisatawan di Ashram Ratu Bagus}

Komunitas ashram yang tinggal di Ashram Ratu Bagus merupakan komunitas spiritual yang terdiri dari murid, keluarga dan staf ashram, mereka merupakan orang-orang mendukung dari misi Ratu Bagus sebagaimana dikutip dalam Narottama (2012), sebagai berikut; "Ashram Ratu Bagus mencerminkan kehangatan dan keramahan masyarakat Bali. Mengujungi ashram, seperti mengunjungi rumah dan keluarga. Komunitas Ashram sebagian besar terdiri dari keluargakeluarga Bali, dengan satu tujuan, yakni mendukung misi dari Ratu Bagus. Mereka berkerja tanpa lelah, dan selalu dengan kebahagiaan." Pada awal pendirian ashram Ratu Bagus menginginkan agar Ashram Ratu Bagus untuk dapat menjadi tempat yang memajukan kehidupan bersama orang-orang yang tinggal didalamnya secara spiritual dan dilandaskan oleh asas-asas kekeluargaan. Komunitas Ashram Ratu Bagus sejak kedatangan wisatawan pertama kali sampai dengan saat ini, selalu ramah dan terbuka lebar terhadap kedatangan wisatawan yang melakukan pembelajaraan spiritual di Ashram Ratu Bagus. 


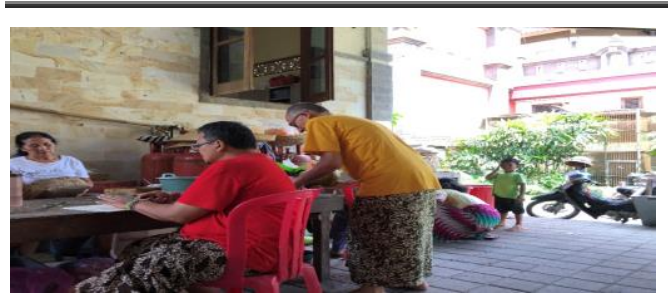

\section{Gambar 7. Piket Dapur Wisatawan} Mancanegara di Ashram Ratu Bagus

Sumber: Dokumentasi Penelitian Lapangan, 2020

Keberadaaan komunitas ashram yang sederhana dan selalu hidup gotong royong membukakan peluang bagi para wisatawan yang berkunjung ke Ashram Ratu Bagus untuk merasakan dan belajar berkehidupan ditengah komunitas ashram yang sederhana dan melakukan berbagai aktivitas bersama-sama. Melalui pembelajaraan spiritual serta pembelajaran berkehidupan dalam komunitas ashram, wisatawan dengan komunitas ashram membentuk hubungan yang saling terikat satu sama lain. Hubungan kekeluargaan yang terbentuk dari hasil jalinan interaksi yang terus menerus dibangun diantara komunitas ashram dengan wisatawan yang berkunjung ke Ashram Ratu Bagus.

Relasi sosial kekeluargaan yang terbentuk antara sisya lokal dan sisya mancanegara dari Ratu Bagus menciptakan lingkungan komunitas ashram yang harmonis, sehingga komunitas ashram dan wisatawan yang hidup berdampingan bersinergi untuk saling melengkapi satu sama lain sebagai satu kesatuan keluarga dari komunitas Ashram Ratu Bagus.

\section{KESIMPULAN}

Berdasarkan hasil penelitian ini, maka dapat ditarik kesimpulan bahwa dalam pola relasi antara komunitas ashram dengan wisatawan di Ashram Ratu Bagus sebagai daya tarik wisata, ditemukan bahwa wisatawan yang berkunjung ke Ashram Ratu Bagus didorong oleh motivasi kejenuhan hidup sehari-hari, keinginan untuk melakukan rekreasi yang serius dan menemukan jati diri mereka atau self-fulfilment. Pola relasi yang terbentuk antara Ratu Bagus dengan wisatawan adalah bentuk relasi guru spiritual, yaitu Ratu Bagus dengan murid, yaitu sisya mancanegara yang berkunjung ke Ashram Ratu Bagus mencari pertumbuhan spiritual, pencarian guru spiritual dan penyembuhan fisik dan mental, sedangkan pola relasi yang terbentuk antara komunitas ashram dengan wisatawan adalah kekeluargaan yang didasarkan dengan pada asas kekeluargaan pada pendirian Ashram Ratu Bagus oleh Ratu Bagus dan kehidupan wisatawan yang bersama komunitas ashram sebagai sesama murid yang saling terikat oleh minat yang sama dan kondisi yang tidak jauh berbeda pada awal mengujungi ashram interaksi yang terjadi terus menerus membangun relasi yang keterikatan antara komunitas ashram dengan wisatawan

Adapun saran dalam penelitian ini yang ditujukkan kepada Ashram Ratu Bagus, wisatawan Ashram Ratu Bagus, pihak eksternal dan kepada akademisi, yaitu Bagi Ashram Ratu Bagus, Ashram Ratu Bagus dapat mempertimbangkan untuk melakukan penambahan jumlah staf atau sumber daya manusia dalam operasional ashram sehari-hari sebagai upaya efektivitas dan regenerasi sumber daya manusia, mengingat jumlah staf yang cukup sedikit dibandingkan jumlah wisatawan yang berkunjung tiap bulan. Dengan penambahan staf dan sumber daya manusia muda diharapkan operasional ashram sehari-hari akan lebih efektif serta dapat terjalin pula hubungan yang dekat antara staf ashram muda dengan wisatawan.

Bagi wisatawan Ashram Ratu Bagus, wisatawan sebagai sisya Ratu Bagus dan telah bersama komunitas ashram dapat terus melakukan Karma Yoga dalam membantu operasional ashram sehari-hari, sehingga relasi yang terbentuk dapat terjaga selalu antara Ratu Bagus, komunitas ashram dan sesama wisatawan, serta wisatawan dapat mencurahkan ide-ide yang dapat membantu perkembangan Ashram Ratu Bagus kedepannya.

Bagi pihak eksternal Ashram, pihak eksternal Ashram yang membaca laporan ini diharapkan dapat mengetahui bahwa dalam praktek wisata spiritual sebagai wisata minat khusus yang dilakukan Ashram Ratu Bagus dapat menjadi acuan mengenai bentuk relasi yang dapat terbangun antara host dan guest yang dimana bila di Ashram Ratu Bagus merupakan komunitas ashram dan wisatawan, hasil kajian mengindikasikan bahwa dalam praktik wisata spiritual khususnya masih terdapat ruang untuk membangun hubungan yang lebih dari sekedar tuan rumah dan tamu, melainkan relasi yang lebih intim sehingga wisatawan yang berkunjung dapat menjadi repeater di daya tarik wisata. Secara praktis pihak eksternal ashram dapat mengoptimalkan relasi yang dibangun dengan wisatawan.

Bagi Akademisi, kajian mengenai pola relasi dan intesitas relasi yang dibahas dalam penelitian ini memberikan ruang baru bagi para akademisi untuk melakukan penelitian dengan topik yang sama di tempat yang berbeda sehingga dapat memberikan hasil yang kompherensif dan holistik dalam menggambarkan pola relasi terbangun terutama pada praktik wisata minat khusus atau khususnya pada praktik wisata spiritual. 


\section{DAFTAR PUSTAKA}

Ariawan, Putu Alex. (2009). Daya Tarik Utama Ashram Ratu Bagus Sebagai Tujuan Pariwisata Spiritual dan Manfaatnya Terhadap Wisatawan Mancanegara di Desa Muncan Kecamatan Selat Kabupaten Karangasem. Tesis. Magister Kajian Pariwisata, Universitas Udayana Denpasar.

Bowen, G. A. (2009). Document analysis as a qualitative research method. Qualitative Research Journal, 9(2), 27-40.

Budarma, I.K., (2012). Akulturasi antara Budaya Wisatawan dan Masyarakat Lokal dalam Kepariwisataan Bali. Jurnal Ilmiah Pariwisata Universitas Udayana (online),2(1), pp.109222.

Fridgen, Joseph. 1991. Dimension of Tourism. East Lansing : American and Hotel Association

Haq, F. dan Jackson, J. (2006). Exploring Consumer Segments and Typologies of Relevance to Spiritual Tourism. Queensland: Central Queensland University.

Ika, I Gusti Ngurah Agung Darma. (2018). Studi Saluran Distribusi Produk Pariwisata Spiritual di Ashram Ratu Bagus. Skripsi. Sarjana Pariwisata. Universitas Udayana Denpasar.

Kastenholz, E., Carneiro, M. J., Eusébio, C., \& Figueiredo, E. (2013). Host-guest relationships in rural tourism: Evidence from two Portuguese villages. Anatolia, 24(3), 367-380.

Kertajaya, Hermawan. (2008). Arti Komunitas. Bandung: Gramedia Pustaka.

Kusmayadi dan Endar Sugiarto. (2000). Metodologi Penelitian dalam Bidang Kepariwisataan. Jakarta: PT. Gramedia Pustaka.

Moleong, Lexy J. (2005). Metodologi Penelitian Kualitatif. Bandung: PT. Remaja Rosdakarya.

Narottama, Nararya. (2012). Wisata Spiritual: Studi Kasus Partisipasi Orang Asing dalam Upacara Pitrayajna di Desa Muncan, Selat, Karangasem, Bali. Tesis. Magister Kajian Pariwisata. Universitas Udayana Denpasar.

Pitana, I G. dan Gayatri, P G. (2005). Sosiologi Pariwisata. Yogyakarta: Andi.

Reid, Donald. G. (2003). Tourism, Globalization and Development Responsible Tourism Planning. London: Pluto Press.

Sochib, M. (2002). Pola Asuh Orang Tua dalam Membantu Anak Mengembangkan Displin Diri. Jakarta: Rineka Cipta.

Soekanto, Soerjono (2007). Sosiologi Suatu Pengantar. PT. Raja Grafindo Persada: Jakarta.

Spradley, James P. dan McCurdy David.W. (1975). Cultural Experience, Ethongraphy in Complex Society. Chicago: Science Reasearch Association.

Su, M. M., Long, Y., Wall, G., \& Jin, M. (2016). Touristcommunity interactions in ethnic tourism: Tuva villages, Kanas Scenic Area,
China.Journal of Tourism and Cultural Change, 14(1), 1-26.

Sugiyono. (2014). Metode Penelitian Kuantitatif Kualitatif Dan R\&D. Bandung: Alfabeta.

----------. (2017). Metode Penelitian Kualitatif (Untuk penelitian yang bersifat: eksploratif, enterpretif, interaktif dan konstruktif). Bandung: Alfabeta.

Sumber Lain:

Sakti, Guntur. (2019). "Siaran Pers : Devisa Sektor Pariwisata Meningkat Mencapai 19,29 Miliar Dolar AS". Diakses dari www.kemenparekraf.go.id pada tanggal 19 Juli 2020.

Tim Ratu Bagus. (2016). "Ratu Bagus, Kehidupannya dan Karyanya". www.ratubagus.com pada tanggal 19 Juli 2020. 